\section{ECCOMAS}

\section{Proceedia}

COMPDYN 2021

$8^{\text {th }}$ ECCOMAS Thematic Conference on Computational Methods in Structural Dynamics and Earthquake Engineering

M. Papadrakakis, M. Fragiadakis (eds.) Streamed from Athens, Greece, 28 - 30 June 2021

\title{
EXPERIMENTAL AND ANALYTICAL INVESTIGATION OF THE STRENGTHENING OF TRADITIONAL TIMBER FRAMES
}

\author{
Ioannis Stavrou ${ }^{1}$, Panayiotis Demosthenous ${ }^{1}$, Stelios Papastylianou ${ }^{1}$ \\ and Milton Demosthenous ${ }^{2}$ \\ ${ }^{1}$ Civil Engineer, MSc Student, Frederick University, Nicosia, Cyprus \\ ${ }^{2}$ Dr. Civil Engineer, Professor, Frederick University, Nicosia, Cyprus \\ eng.dm@frederick.ac.cy
}

\begin{abstract}
This paper deals with the experimental investigation of the behavior of timber frames with or without infill panels. The examined infill panels are diagonal timber bracers, masonry infill and OSB. The main scope of this effort is the investigation of the influence of the infill panels to the strengthening and the global behavior of these frames. At the first stage the mechanical properties of the used materials, such as timber, brick, mortar and masonry were defined through experimental tests. An additional number of tests were completed in order to define the capacity of the joints between two timber members focused on the shear capacity and the extraction of nails which used for the connection of timber members. All these data will be used for the numerical simulations of the experimental studied timber frames. At the second stage, eight timber frames were designed, constructed and tested at the metallic reaction frame of Frederick University under lateral monotonic loadings until the ultimate limit state. The lateral loading as well the lateral displacement and the uplift of the column which was under tension were measured and recorded using a data acquisition system. At the same time the observed modes of failures were reported. At last, but not least, the evaluation of these measurements through various analytical methods was completed. Through this effort the relation between the lateral displacement and the uplift is examined, the absorbed energy from each timber frame is estimated and the contribution of each infill system to the global behavior of the timber frame systems is defined and discussed.
\end{abstract}

Keywords: Timber frame, infill panels, experimental investigation, analytical evaluation 


\section{INTRODUCTION}

The majority of the historic buildings, both in Eastern Mediterranean region and throughout Europe, were built with load-bearing masonry wall system. Of particular interest, is the timber frame with masonry infill. A masonry timber frame is consisted by many parts created by horizontal, vertical and diagonal timber elements (fig. 1). The ease of construction, on one hand and the availability of the natural material, on the other hand, played an important role, on the wide use of the system throughout the world. The long term existence of this system, proves its efficiency and its durability throughout the centuries. Even today, the timber frame system, in various forms and types, still plays a leading role in the Building industry. Many experimental and numerical investigations have dealt with the behavior and response of this system. Many of them are presenting a qualitative evaluation of this system, under static and seismic loading. While, this study evaluates, with the aid of experimental approach, the behaviour of various strengthening typologies of the system, in a way that this would be helpful to the maintenance and even strengthening procedures of existing structures $[1,2,3,4]$.

An experimental investigation approach, aiming to the strengthening techniques of historic timber frames is designed and is under develop at the Frederick University in Cyprus. The present study is focused on the basic part of a timber frame as explained above, as the first step of this effort in order to understand well the behavior of such systems under lateral seismic loadings, the mechanisms of failure as well the contribution of various techniques for the strengthening of masonry timber frames. Therefore, eight (8) different timber frame specimens with various techniques of strengthening were designed, constructed and tested under monotonic lateral static loading. At the first stage the mechanical properties of the used materials, such as timber, brick, mortar and masonry were defined through experimental tests. An additional number of tests were completed in order to define the capacity of the joints between two timber members focused on the shear capacity and the extraction of nails which used for the connection of timber members. All these data will be used for the numerical simulations of the experimental studied timber frames. During the experimental sequence of frame specimens, a monitoring and data acquisition system was used for the recording of the lateral loading and the horizontal displacement on the top of the frames. In addition to that, the uplift of column which is under tension was recorded during the loading procedure. All these results are evaluated, presented and discussed in what follow with emphasis on the contribution of various strengthening techniques on the behavior of these frames.
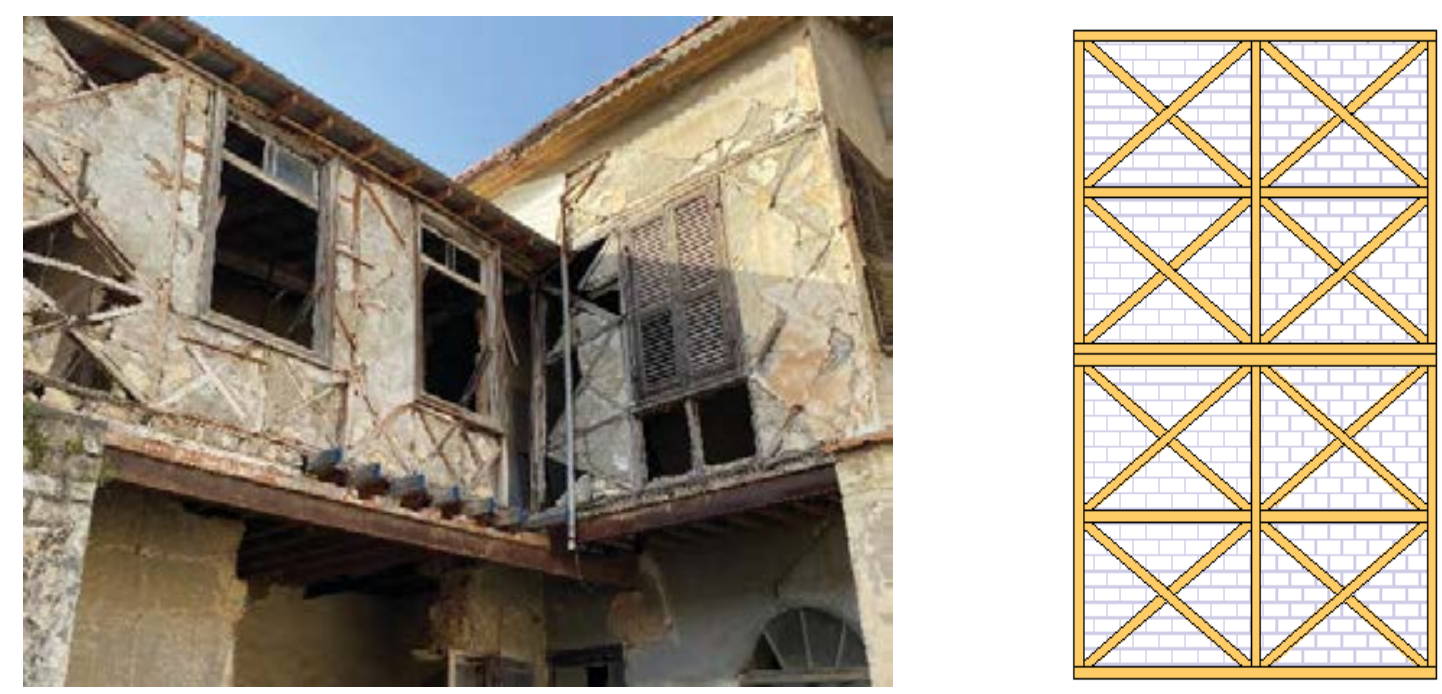

Figure 1. Masonry timber frames on the upper storey of building structure in Cyprus 


\section{DESIGN AND CONSTRUCTION OF THE EXPERIMENTAL TIMBER FRAMES}

\subsection{Mechanical properties of the materials}

A number of tests were completed for the definition of the mechanical properties of the used materials such as timber, brick, mortar and masonry. The properties of these materials will be used for the numerical simulations and structural analysis of experimental frame specimens.

For the construction of masonry walls, lime mortar and bricks were used. Their mechanical properties were defined according to the provisions of European standards. The compressive strength of masonry was defined using triplet specimens (consisted by three breaks connected with mortar) and was founded out equal to $13.2 \mathrm{Mpa}$.

It is well known that timber is orthotropic material. Therefore, the used timber for the construction of timber frames was tested under compression loadings in two cases, parallel and perpendicular to the grain, again according to the provisions of European standards. For each case three specimens were tested. The results from these tests are presented in figure 2 in terms of stress - strain.

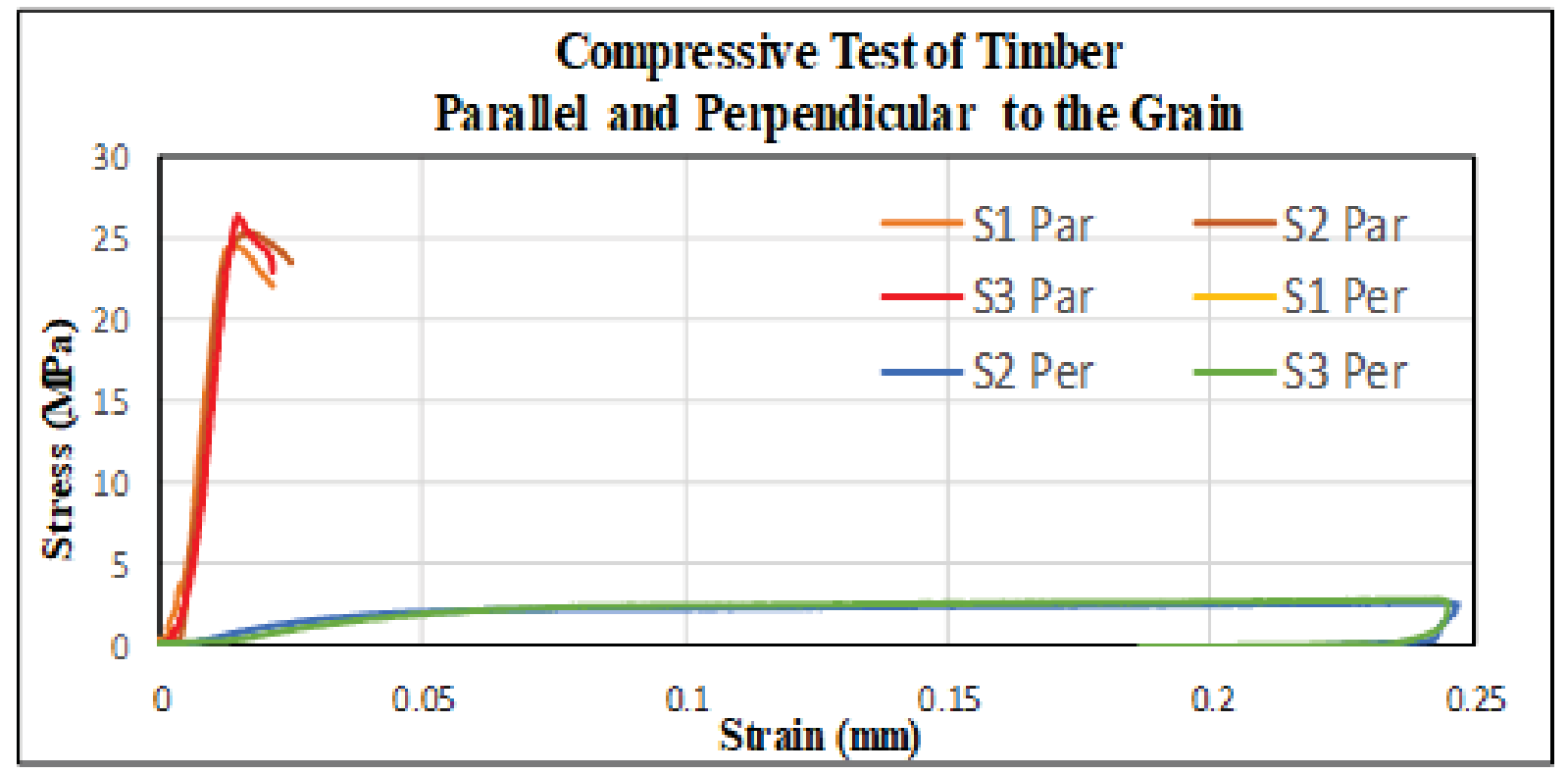

Figure 2. Stress - strain curves of timber under compression

\subsection{Capacity of the joints of timber elements}

All the timber elements were connected with nails. The capacity of these joints is characterized by the shear resistance and resistance to the extraction of the nails under axial tension. Therefore a number of experimental tests were completed to define the shear capacity and the capacity to the extraction of nails. In both cases (shear and extraction capacity) the tests includes various number of nails (one, two or three) for the connection of timber elements.

For the extraction of the nails six specimens were tested. In three of them the timber elements were connected with two nails and in the case of the other three specimens three nails were used. For the shear capacity five specimens were tested. Each specimen was consisted by three timber elements arranged in parallel configuration. The central one was connected 
with the external timber elements using nails. For two specimens two nails were used $(1+1)$ and for three specimens four nails $(2+2)$.

During the tests, the applied loading (shear or tension) and the displacement between the connected timber elements were measured. In any case, after the completion of each test, the capacity corresponds to one nail was estimated. These results are noted in figures $3 \& 4$. In the same figures, the average value of the capacity of one nail is given with a solid line.

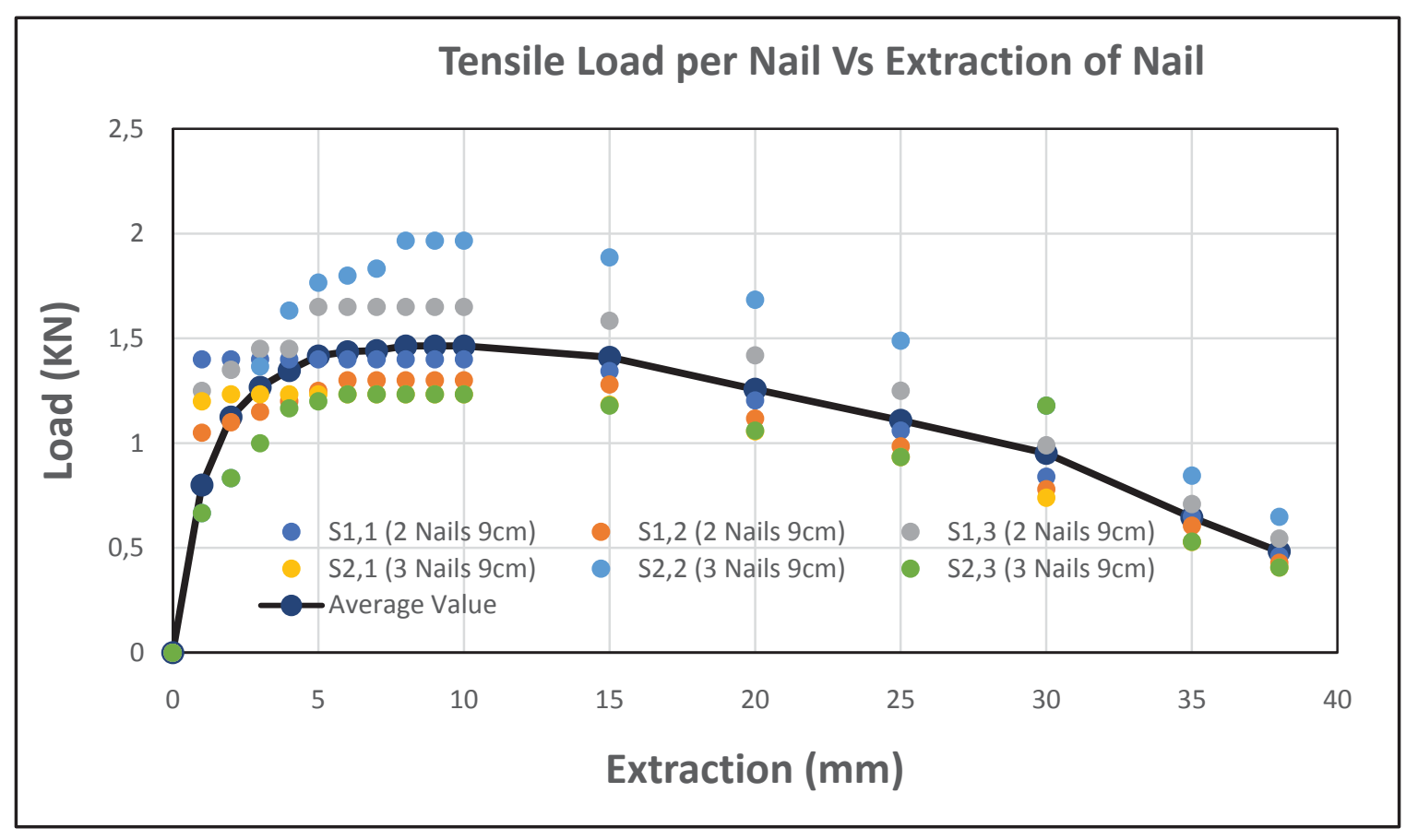

Figure 3. Experimental measurements from the extraction of nails tests

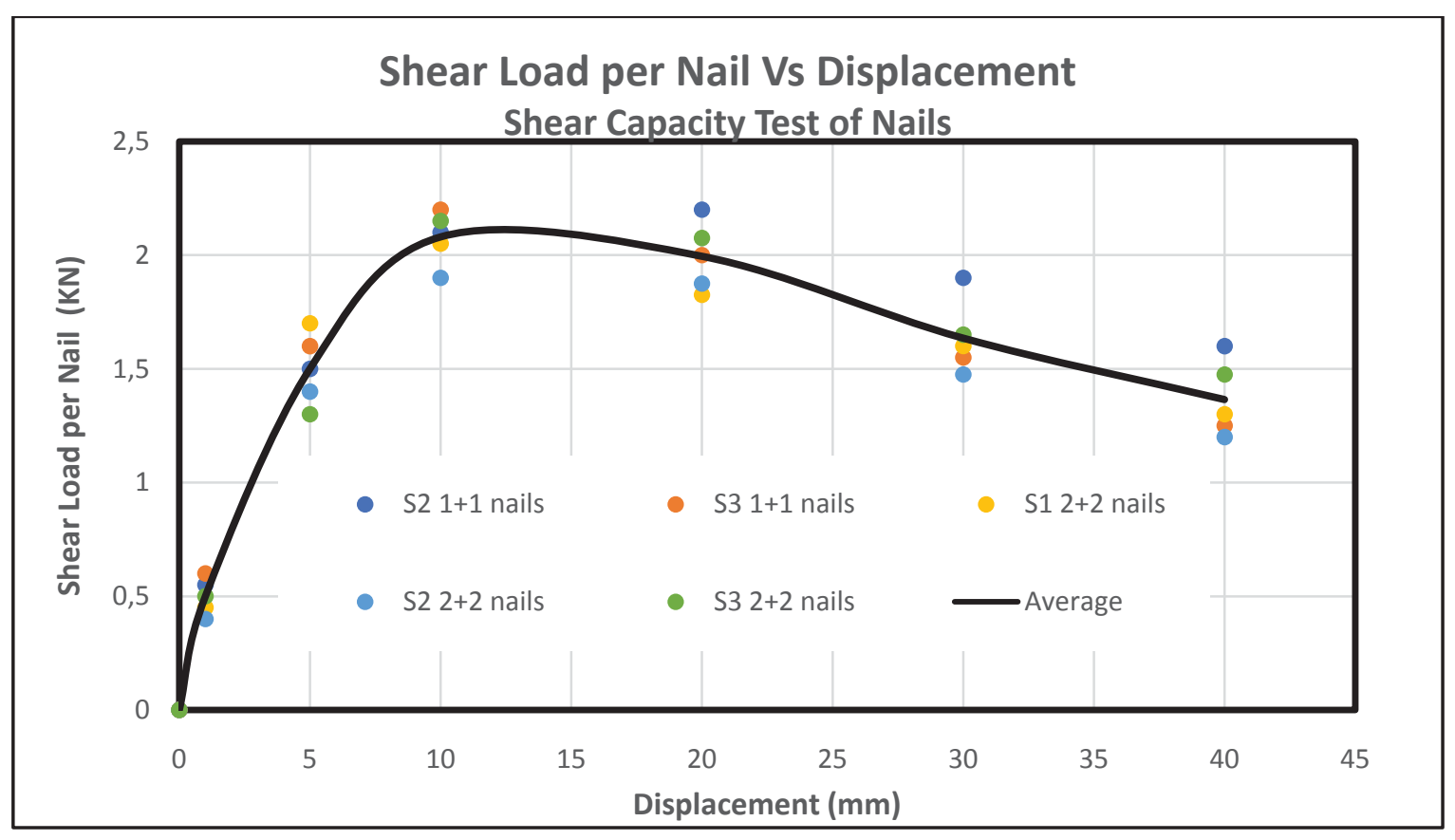

Figure 4. Experimental measurements for the shear capacity nails 


\subsection{Design and construction of experimental timber frames}

As mentioned above, the experimental specimens examined in this paper represent a basic part of a real timber frame (see figure 1) in order to understand well the behavior and the failure mechanisms of such sub-system as basic background to understand and explain these topics of a whole frame system as well to understand and record the influence of various strengthening techniques to the behavior of timber frames such as diagonal timber bracers, masonry infill and the OSB as infill panel. Therefore, eight (8) timber frames in various forms were designed and constructed (figure 5). All experimental timber frames have rectangular shape with height $0.77 \mathrm{~m}(77 \mathrm{~cm})$ and the same bay between the two vertical timber columns $(77 \mathrm{~cm})$.

- The first frame, which will be referred as reference frame in what follow (2CTF), consisted by an horizontal timber beam as base level. Two vertical columns are connected at the base beam with nails. The top level of these columns are connected also with a timber beam using nails.

- The second one has the same configuration, however one more timber column is attached at the middle of the bay (3CTF).

- The third one has also the same configuration with the reference frame including diagonal timber bracers (2CXTF).

- The fourth one is the same with the reference one but with masonry infill (2CMTF).

- The fifth one, as timber frame, is the same with the third one including also masonry infill (2CXMTF).

- The sixth one has the same timber skeleton with the reference one however two OSB panels were used as infill panel attached in both sides of the frame (2CTF - 2- OSB).

- The seventh one has the same timber skeleton with the third one (with diagonal bracers) but only one OSB panel was attached at one side (2CXTF - 1- OSB).

- The eight one has the same timber skeleton with third one (with diagonal bracers) but in this case two OSB panels were used as infill panel attached in both sides of the frame (2CXTF - 2- OSAB).

The facade of all the above experimental timber frames are presented in figure 5.

\section{EXPERIMENTAL TESTS OF TIMBER FRAMES}

\subsection{Experimental setup}

All experimental timber frames were attached at the metallic reaction frame of Frederick University and were subjected to lateral monotonic loading (figure 6). The timber beam at the base of the frames was fixed at the horizontal steel beam of the reaction frame. The lateral loading was applied at the top of the timber frame using an hydraulic jack. In order to avoid local modes of failures due to the point load, an additional timber beam was fixed at the top beam of the frames with an expansion to the hydraulic jack. Therefore, the lateral load was applied in uniform distribution to the top beam of the timber frames.

Two displacement transducers (LVDT) were used to measure the displacements of the timber frames. The first one measured the horizontal displacement at the top of the timber frames. The second one was attached at the base of the frame in order to measure the uplift of the timber column which was under tension during the experimental loading. This uplift was happened due to the extraction of the nails which connected the timber column with the beam at the base level. The measurements of the LVDT' s as well the loadings applied from the hydraulic jack were restored in a data acquisition system in time domain. 


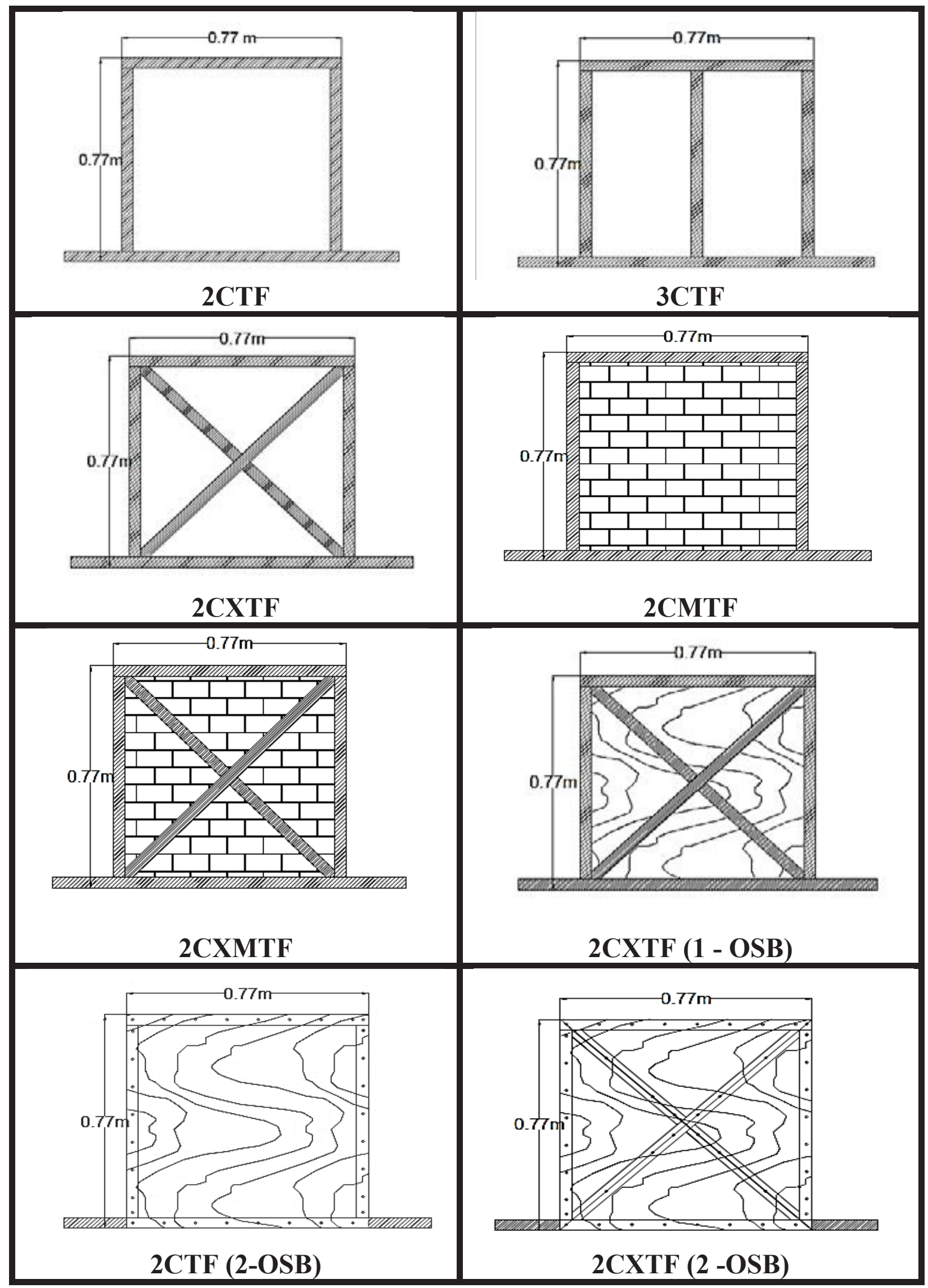

Figure 5. Configuration and dimensions of experimental timber frames 

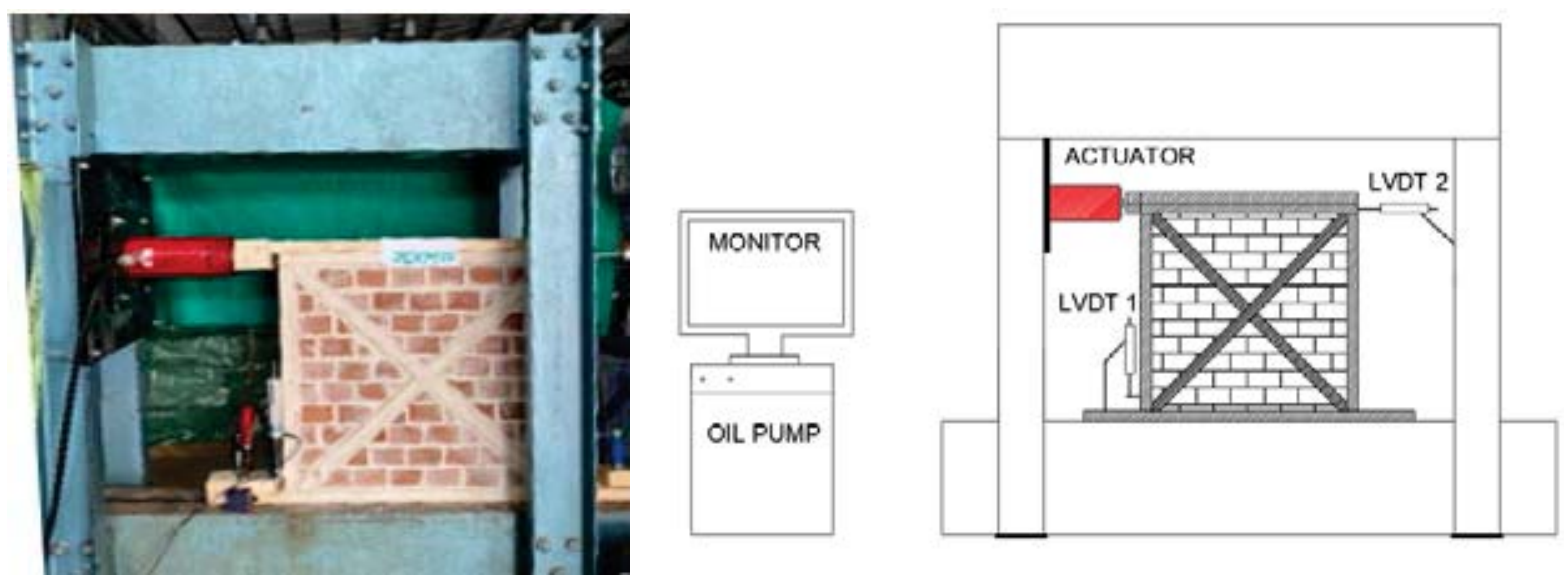

Figure 6. Experimental setup

\subsection{Experimental measurements}

The lateral horizontal load vs the horizontal displacements for all the timber frames are presented in figure 7. We can see that the timber frames $2 \mathrm{CTF}$ and $3 \mathrm{CTF}$ (pure frames) have almost the same behavior with the lower level of the lateral received load but with higher level of lateral displacements without uplift. The timber frames with OSB can receive the higher level of the external loading. The other timber frames (with masonry infill or/and diagonal bracers), simulating traditional timber frames, have a capacity between the two previous categories as mentioned above (pure timber frames and timber frames with OSB).Similar observations can be made and for the measurements of the uplift at the bottom of the left timber column with tensile stress (figure 8).

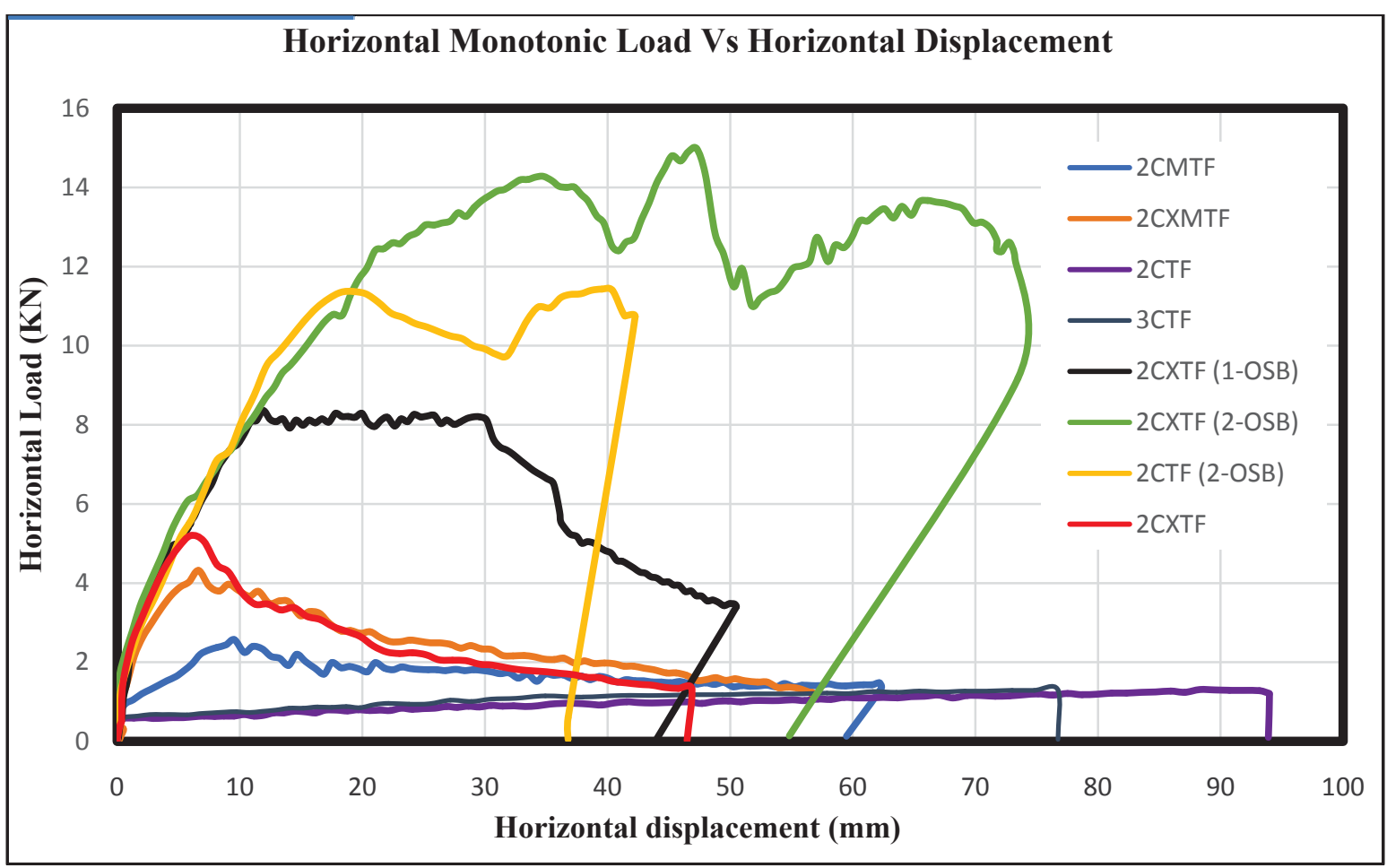

Figure 7.Hrizontal monotonic load vs horizontal displacements 


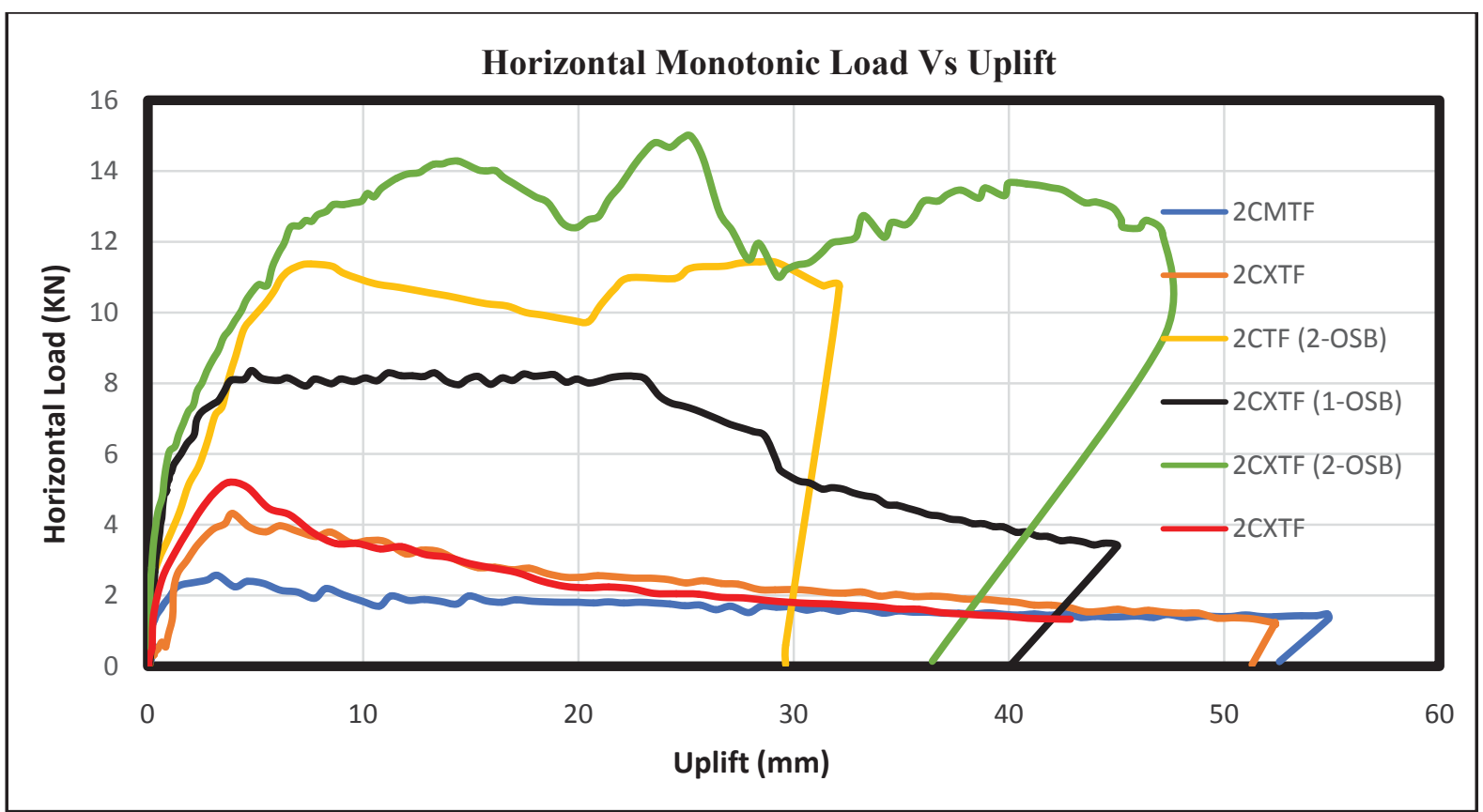

Figure 8. Horizontal monotonic load vs Uplift of the left timber column

\subsection{Observed damages}

The pure frames consisted only by columns and beams (2CTF \& 3CTF) developed only horizontal displacements without any uplift at the left column. After the un-load of these frames a remain displacement was observed. The deformation shape of these frames it looks like pure shear deformation which is mean that the actual resistance during the test was the shear resistance of the nails which connected the timber structural elements (figure 9).

In the case of timber frames with diagonal bracers (2CXTF \& 2CXTF (1-OSB)) the behavior is characterized by horizontal displacements and uplift of the left column at the base level as well the uplift of the diagonal timber element connected at this joint. After the un-load of these frames a remain displacement was observed as well uplift at the base level due to the extraction of the nails (figure 9).

The timber frames with masonry infill develop similar behavior with those with diagonal timber bracers including remain uplift and horizontal displacement after un-loading. However in this case it was founded out that there are significant damages on the masonry infill characterized by disconnection from the timber frame as well diagonal shear cracks were observed. These damages are more serious in the case of timber frame without diagonal timber bracers (2CMTF). In addition to that, a flexural deformation on the left column was observed due to the interaction between the masonry infill and the left timber column (figure 9).

The last two timber frames with OSB infil (2CTF - 2- OSB \& 2 CXTF -2 -OSB) developed much difference behavior. Due to the OSB infill panel which was connected with the surrounding frame (columns and beams), the beam at the base level developed flexural deformation created by vertical loadings applied through the connections of the beam with the OSB. After the un-load of these frames the remain displacement and uplift was observed to be much smaller than the previous cases. However, a flexural deformation is remained at the beam at the base level (figure 9). 

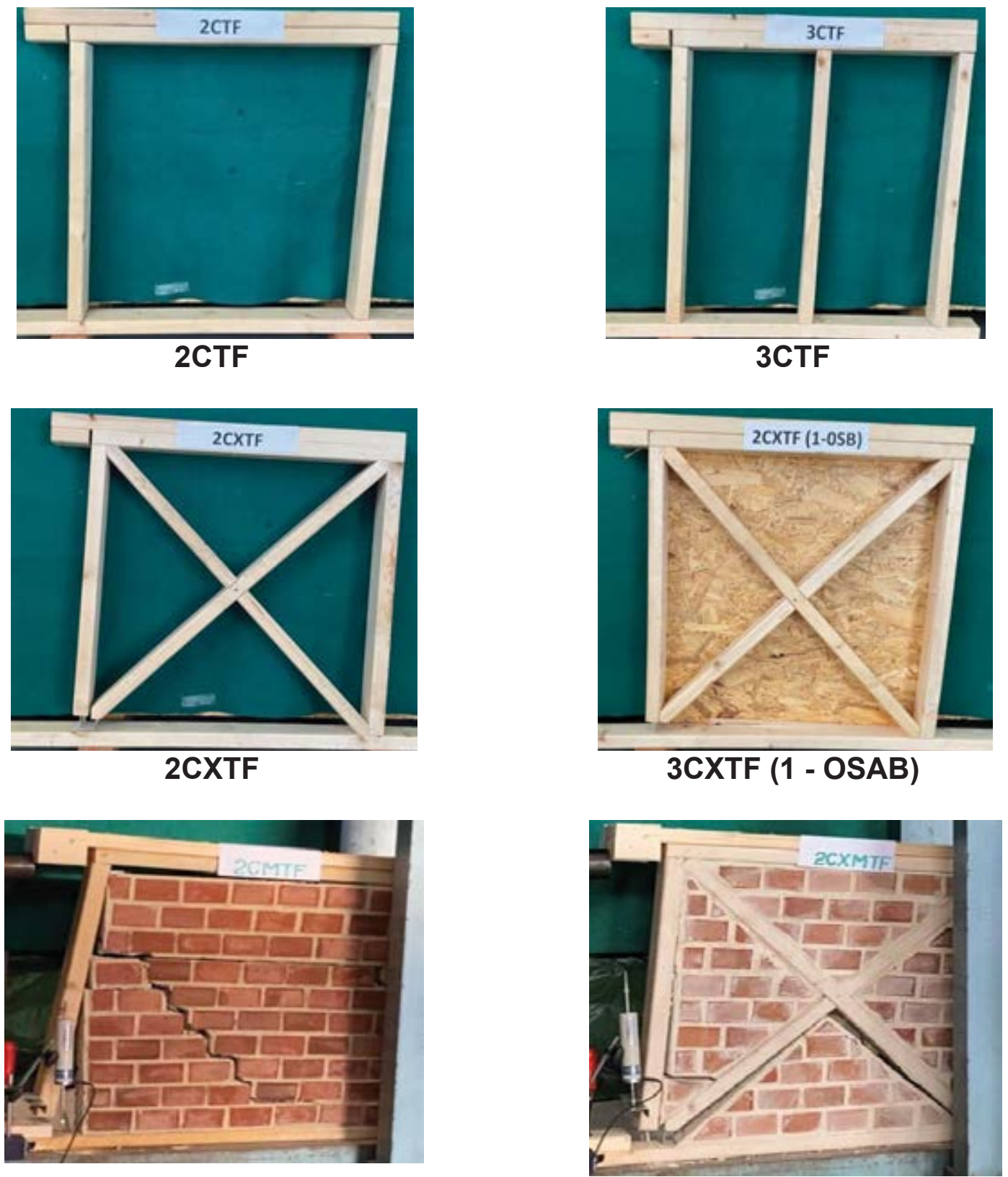

2CMTF
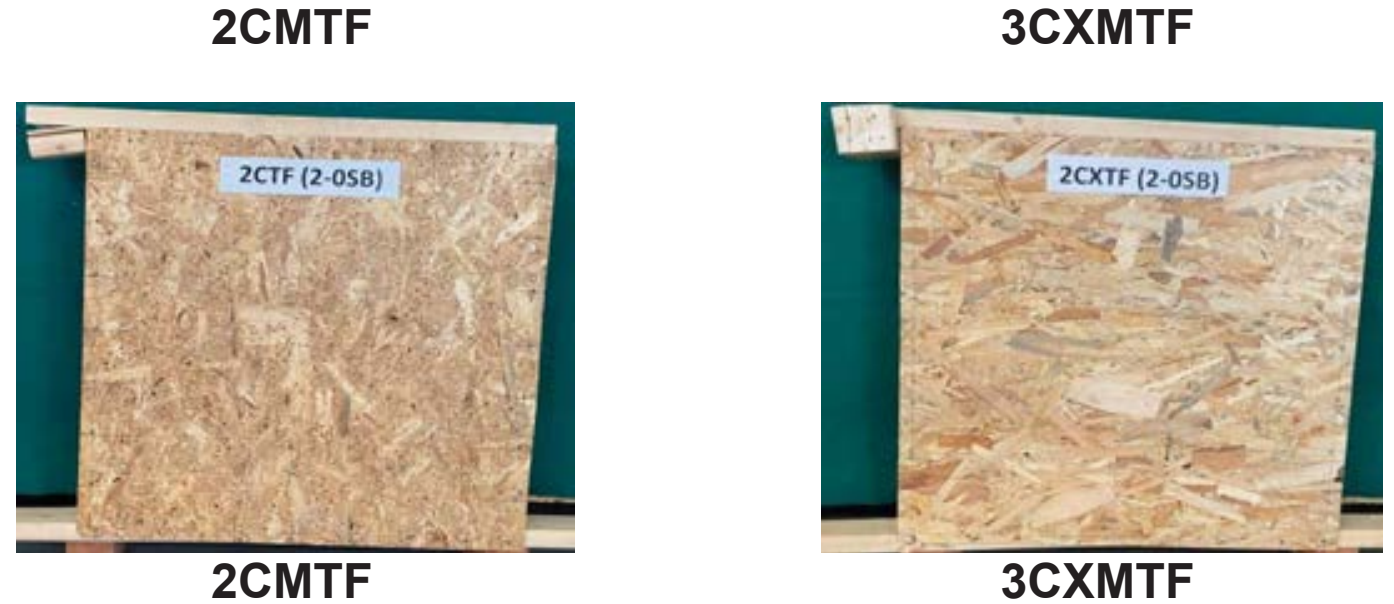

Figure 9. Modes of the observed failures of the timber frames 


\section{EVALUATION AND ANALYSIS OF THE EXPERIMENTAL MEASUREMENTS}

\subsection{Evaluation and analysis of the horizontal displacements of the timber frames}

In this section the horizontal displacements of the timber frames are examined until the max. lateral load (Fmax) with the assumption of linear behavior. From this point of view, the total horizontal displacement $(\mathrm{X})$ of each frame is consisted by two parts $(\mathrm{X} 1+\mathrm{X} 2)$. The first one (X1) is created due to the uplift. Assuming of a rigid body rotation of the frame system, the $\mathrm{X} 1$ is equal to the uplift (X1=uplift). However, an additional horizontal displacement (X2) is created due to the shear and bending deformation of the timber frame. This approach is presented in figure 10. The values of the X (total displacement), the X1 and the X2 are presented in figure 11 for six timber frames which developed uplift during the tests.

At a second step, the values of the X1 and X2 are divided by the total displacement (X) in order to find the contribution of each part to the total displacements in percentage (figure 12). As can be seen, in the case of masonry infill timber frame without diagonal bracers (2CMTF) the contribution from the uplift to the total displacement is more than $75 \%$, however in the case of masonry timber frame with diagonal bracers (2CXMTF) this contribution is reduced approximately up to $55 \%$. In the case of timber frame with diagonal bracers (2CXTF) the contribution from the uplift is approximately about 33\%. The more significant observation from this analysis is that, all the frames with OSB infill panel the contribution from the uplift (X1) to the total displacement $(\mathrm{X})$ is almost the same in all the cases, approximately up to $42 \%$. From this point of view it can be said that the behavior of timber frames with OSB infill panel is more predictable. However, this observation must be verified through a numerical investigation.

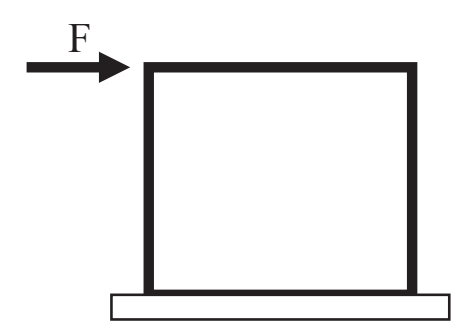

Analysis of the Deformation shape: $\mathrm{X}=\mathrm{X} 1+\mathrm{X} 2$

Deformation

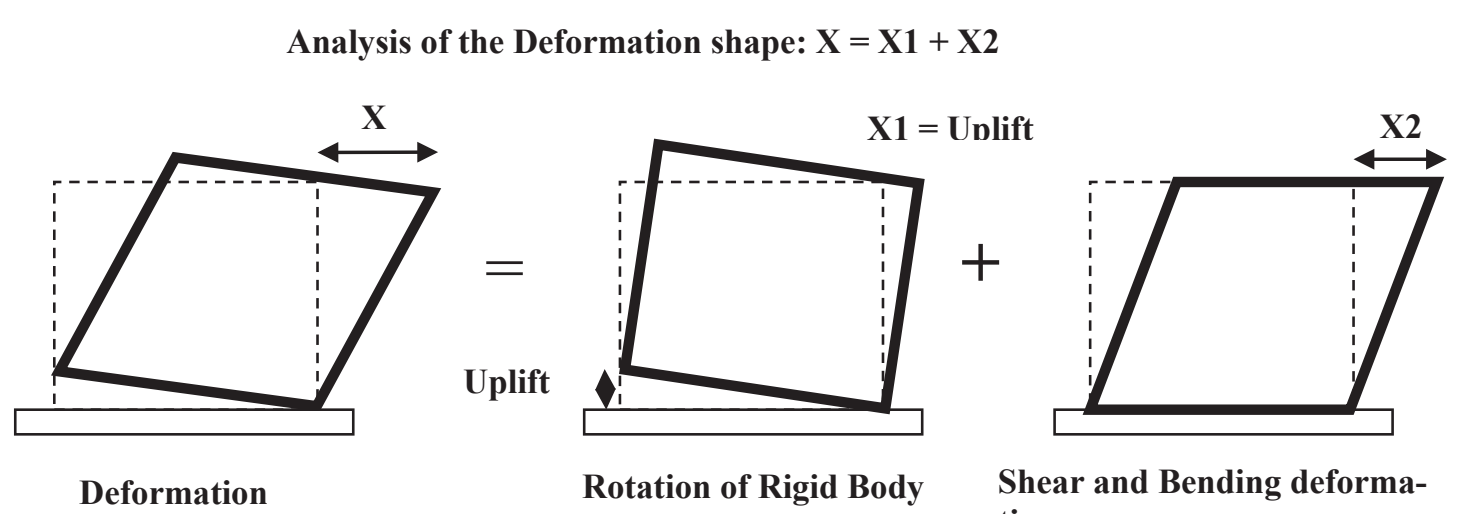

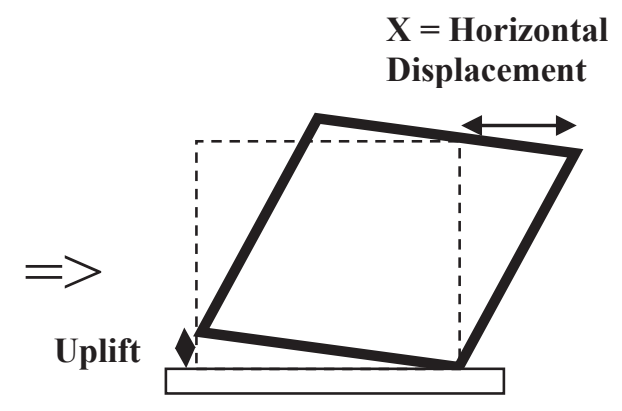

Deformation shape of the Structural System

Figure 10. Analysis of the total displacement 


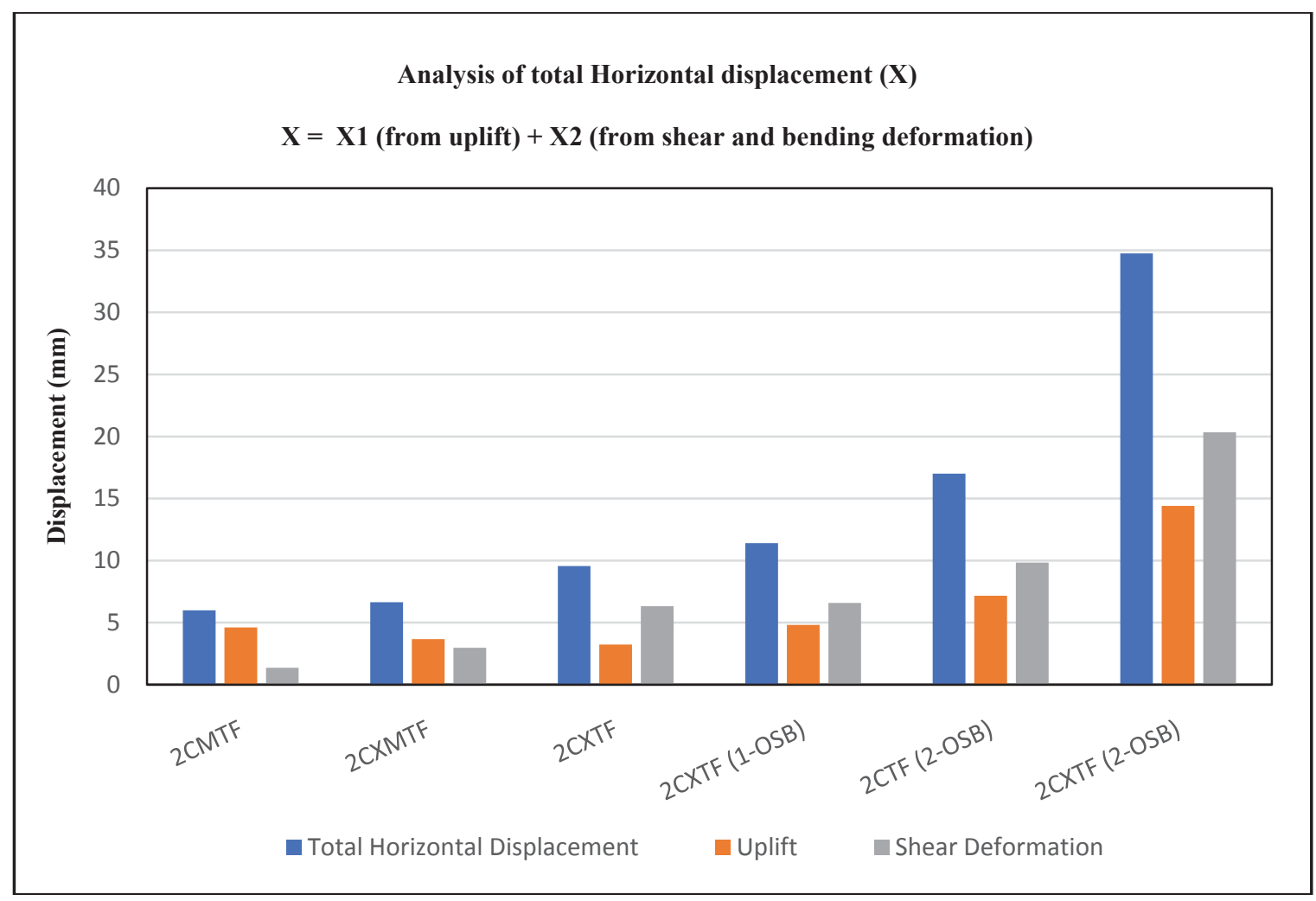

Figure 11. Analysis of the total displacement

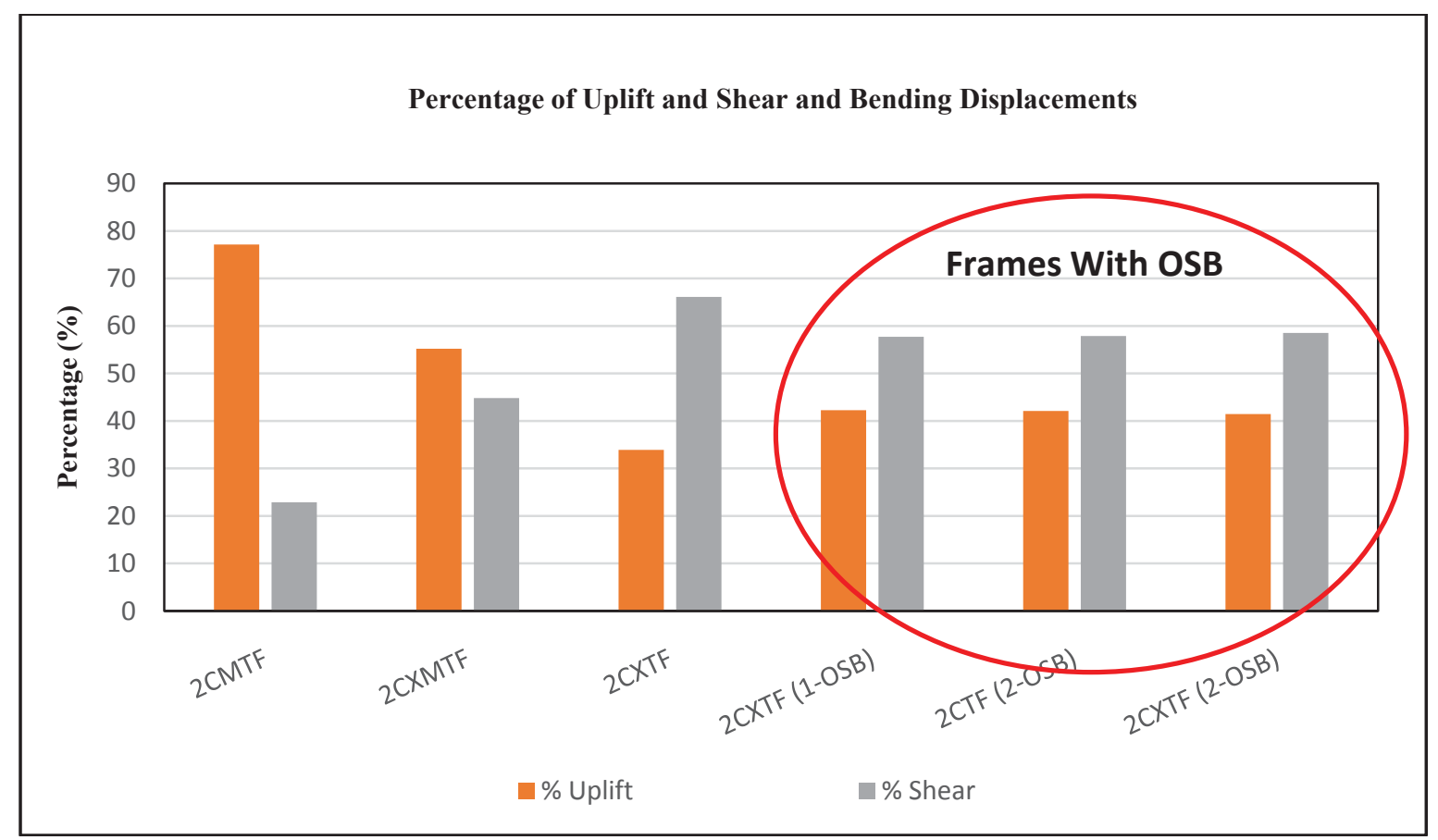

Figure 12. Percentage contribution of uplift and shear and bending deformation to the total horizontal displacement 


\subsection{Evaluation and analysis of the global behavior of the timber frames and contribution of the strengthening techniques}

The main scope of this effort is to investigate the influence of the strengthening techniques to the global behavior of the studied timber frames. For that, the quantity of energy absorbed by each frame and the correlation of this energy with that of the reference frame (2CTF) is presented. For each timber frame, the absorbed energy was estimated by the area below the curve of Lateral Force Vs Horizontal Displacement as defined by the experimental measurements. This absorbed energy was estimated until 40mm horizontal displacement for all the studied frames (figure 13). After that, the absorbed energy of each frame is correlated with absorbed energy of the reference frame $(2 \mathrm{CTF})$. The results from this effort are presented in table 1.

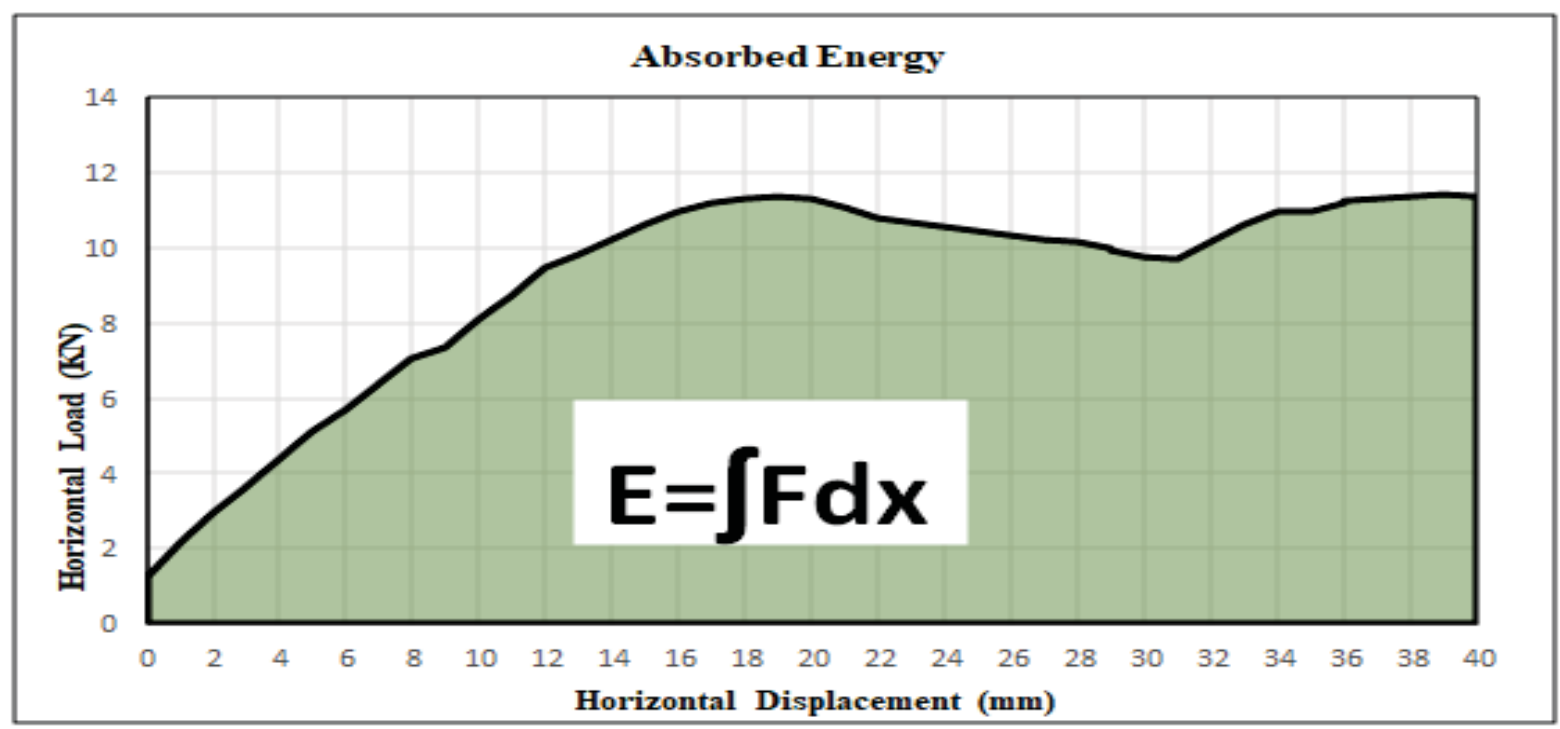

Figure 13. Procedure for the estimation of the absorbed energy for each timber frame

\begin{tabular}{cccc}
\hline Timber Frame & $\begin{array}{c}\text { Absorbed Energy } \\
(\mathrm{J})\end{array}$ & $\begin{array}{r}\text { Ratio of Absorbed Energy } \\
\text { (frame i / 2CTF) }\end{array}$ & $\begin{array}{c}\text { Increasing of } \\
\text { Absorbed Energy }\end{array}$ \\
\hline 2CTF & 32.5 & 1.00 & $0.0 \%$ \\
3CTF & 40.6 & 1.24 & $24 \%$ \\
2 CMTF & 73.75 & 2.26 & $126 \%$ \\
2 CXTF & 113.0 & 3.47 & $247 \%$ \\
2 CMXTF & 114.0 & 3.50 & $257 \%$ \\
2 CXTF (1 - OSB) & 277.35 & 8.53 & $753 \%$ \\
2 CTF (2 - OSB) & 363.4 & 11.21 & $1021 \%$ \\
2 CXTF (2 - OSB) & 429.7 & 13.22 & $1222 \%$ \\
\hline
\end{tabular}

Table 1. Result from the estimation of the absorbed energy and correlation with the reference frame (2CTF) 
At a second step, the contribution of each strengthening technique to the increasing of the absorbed energy is examined. For that, the contribution of an additional vertical timber column, the masonry infill, the diagonal timber bracers and the OSB as infill panel are examined. In the first stage the difference in absorbed energy between two timber frames with only difference the examined strengthening technique is estimated. If there were more cases with that, the average value of them was taken in the account. Finally the amplification factor for each intervention technique was estimated. This amplification factor describes how many times there is increasing of the absorbed energy of the reference frame (2CTF) if the strengthening technique would be applied on the reference frame. The results from this procedure are summarize in table 2. According to these results, it can be said that the panel of one OSB has much higher contribution to the absorbed energy than the other strengthening techniques. Actually the contribution of one panel of OSB is more than two times than that from the diagonal bracers and almost four times than that form the masonry infill. At last, but not least, it can be said that the additional vertical timber column has very low contribution to the absorbed energy, however this technique must be examined in various cases and structural configurations for more safety and realistic conclusions.

\begin{tabular}{|c|c|c|c|c|}
\hline $\begin{array}{l}\text { Strengthening } \\
\text { Technique }\end{array}$ & Formula & $\begin{array}{c}\text { Absorbed } \\
\text { Energy } \\
(\mathrm{J}) \\
\end{array}$ & $\begin{array}{l}\text { Average } \\
\text { value }\end{array}$ & $\begin{array}{c}\text { Amplification } \\
\text { factor } \\
\text { (Str. tech./2CTF) }\end{array}$ \\
\hline $\begin{array}{c}\text { Additional } \\
\text { one vertical column }\end{array}$ & $3 \mathrm{CTF}-2 \mathrm{CTF}$ & 8.1 & 8.1 & 0.25 \\
\hline Masonry infill & $2 \mathrm{CMTF}-2 \mathrm{CTF}$ & 41.25 & 41.25 & 1.3 \\
\hline \multirow[t]{2}{*}{ Diagonal bracers } & $2 \mathrm{CXTF}-2 \mathrm{CTF}$ & 80.5 & 73.5 & 2.25 \\
\hline & 2CXTF (2OSB) - 2CTF (2OSB) & 66.3 & & \\
\hline \multirow[t]{3}{*}{1 OSB panel infill } & 2CXTF (1OSB) - 2CXTF & 164.35 & 162.7 & 5.0 \\
\hline & {$[2 \mathrm{CXTF}(2 \mathrm{OSB})-2 \mathrm{CXTF}] / 2$} & 158.35 & & \\
\hline & {$[2 \mathrm{CTF}(2 \mathrm{OSB})-2 \mathrm{CTF}] / 2$} & 165.45 & & \\
\hline
\end{tabular}

Table 2. Contribution of each strengthening technique to the absorbed energy

\section{CONCLUSIONS}

The behavior of eight (8) timber frames was investigated under lateral monotonic loadings through an extended experimental investigation accompanied by the analysis and the evaluation of the experimental measurements. The reference timber frame was consisted by two vertical columns connected at the base level and at the top level with horizontal beams. The timber elements were connected with nails. All the other timber frames were strengthened using various strengthening techniques, such as additional vertical timber column, masonry infill, diagonal timber bracers and OSB as infill panel. According to the observed damages and the evaluation of the experimental results, the followed conclusions can be made: 
- The predominant modes of the observed failures can be characterized by the uplift of the vertical timber column which was under tension, due to the extraction of the nails at the base level, as well by shear and bending deformation of the frame. After the unloading of the experimental frames, significant remained displacement of all the examined frames was observed.

- In the case of the timber frames with masonry infill, sliding and disconnection of the masonry infill from the surrounding frame accompanied also by cracks of the masonry infill were occurred.

- In the case of timber frames with OSB as infill panel, a flexural deformation at the bottom beam was observed due the connection of this beam with the OSB.

- It was founded out that the max. values of the received lateral load (Fmax) is strongly depended by the strengthening technique with those of the timber frames with OSB to received much higher max. horizontal load than the other cases.

- The total displacement is consisted by two parts. The first one is the contribution from the uplift and the second one is the contribution from the shear and bending deformation of the frames. This contributions are varied however in the case of timber frames with OSB were founded to be constant.

- Finally, the increasing of the absorbed energy by the OSB it was founded out that is much higher than the absorbed energy by the frames strengthened with other techniques. Also, the diagonal bracers has almost two times higher contribution in the absorbed energy than that by the masonry infill.

\section{REFERENCES}

[1] Dima DI, Dutu A. Traditional buildings with timber frame and various infills in Romania. Presented at the World Conference on Timber Engineering (WCTE), Wien, Austria; 2016.

[2] Gólkan P, Langenbach R. The earthquake resistance of traditional timber and masonry dwellings in Turkey. Presented at the 13th World Conference on Earthquake Engineering (WCEE), Vancouver, B. C., Canada; 2004.

[3] Dutu A, Niste M, Spatarelu I. In-plane static cyclic tests on traditional Romanian houses' walls. Presented at the 16th European Conference on Earthquake Engineering (ECEE), Thessaloniki, Greece; 2018.

[4] Makarios, T., and M. Demosthenous. 2006. Seismic response of traditional buildings of Lefkas Island. Greece, Engineering Structures 28:364-295. 